\title{
INFLUENCIA DEL PENSAMIENTO KEYNESIANO EN LA POLÍTICA ECONÓMICA PERONISTA (1946-1955)
}

Al Dr. Lascar Saveamu, uno de los padres fundadores de los estudias de Economia en la Universidad Nacional del Sur, mi maestro, in memoriam.

\section{Introducción}

Intentaremos analizar brevemente en este trabajo el periodo de la historía económica y la política económica desarrollada en la Argentina durante la segunda posguerra mundial.

Veremos cuáles son los rasgos keynesianos de la misma, en qué periodo se manifiesta más claramente y en qué sentido se puede hablar de keynesianismo en referencia a la política económica del primer peronismo.

\section{Antecedentes. El marco internacional}

Después de la gran guerra comienza a tambalear el viejo orden económico internacional.

Durante la guerra el sistema monetario del patrón oro habia dejado de funcionar: se suspende la convertibilidad y se prohibe la exportación de oro.

Durante la década del ' 20 se intenta reflotar el sistema monetario tradicional pero no se lo logra plenamente. En 1931 Inglaterra abandona el patrón oro y la siguen muchos otros países. La decisión norteamericana del 20 de abril de 1933 de abandonar el patrón oro se considera el fin de dicho sistema a nivel internacional. En la década del '30 se ve seriamente afectado el comercio multilateral.

Cada pais trataba de salvarse. Se comienzan a desarrollar políticas proteccionistas, control de cambios, restricciones a la importación, etc. 
Dominan los acuerdos bilaterales en el comercio internacional. En todo este período Inglaterra va cediendo su puesto de centro dinámico principal del capitalismo que se desplaza hacia los Estados Unidos.

En la década del '20 el progreso fue asombroso especialmente durante el ciclo 1923-1929. Hay un crecimiento notable de la inversión, el ingreso, la demanda y la ocupación. El crédito abundante acompañó el proceso; la emisión de acciones creció hasta dar lugar a la especulación. El 29 de octubre de 1929 explota la Bolsa de Nueva York, como punto final de la ola especulativa. Sigue una depresión muy profunda y amplia de características no conocidas hasta entonces. Caen el consumo, las ventas, la producción, se acumulan stocks, caen los salarios. Pero el rasgo más destacado de la depresión es la gran masa de desocupados.

Asume Roosevelt en marzo de 1933 y con su Brain Trust se fijan como objetivo aumentar la producción a través del aumento de la demanda.

Entre las medidas del New Deal se destacan: el uso intensivo del crédito, obras públicas, ayuda a los desocupados. Finalmente el abandono del patrón oro. Se crea la National Industrial Recovery Act que permitía al gobierno regular la producción industrial y las relaciones entre empresas. También la National Recovery Administration.

En el sector agrario se crea el Agricultural Adjustment Administration que brindaba subsidios. Se limitan las áreas sembradas con el objeto de elevar los precios agropecuarios. La Trade Agreement Act permitió al gobierno mejorar la situación en relación al comercio exterior. Hay un amplio programa en vinculación con el mejoramiento de los trabajadores: se fomenta el sindicalismo, se establecen salarios mínimos, la seguridad social y el acceso a las viviendas baratas.

Hacia 1936 termina la depresión. Como consecuencia surge un sistema capitalista mixto, con fuerte intervención del Estado en la economía, tan revolucionario en relación con lo anterior que incluso le cuesta a Roosevelt enfrentarse con la Suprema Corte de Justicia que declara inconstitucional las intervenciones en el sector agrario e industrial. El New Deal ejerce profunda influencia no sólo en los Estados Unidos sino en muchos otros países, incluido el nuestro. La seguridad social, el impuesto a los réditos, el gasto público que adquiere mucho mayor nivel, la reforma bancaria y monetaria que tiende a unificar y respaldar el sistema, las políticas anticíclicas y en fin, el rol privilegiado que tendrá en adelante, el Estado. 


\section{John Maynard Keynes y sus ideas principales}

Dice de J. M. Keynes (1883-1946), el Dr. Vázquez Presedo: "Filósofo, matemático, polemista, orador político, civil servant, crítico de todo lo que se hacía y deshacía en el mundo de su época, nada le era ajeno salvo la ignorancia y la mediocridad. Era una de esas raras criaturas que justamente por entender mucho, entienden las cosas del cielo y las de la tierra". ${ }^{.}$

Ya en su obra Las Consecuencias Económicas de la Paz, condena las excesivas reparaciones impuestas a Alemania por la Paz de Versailles y prevé consecuencias perniciosas. Allí aparecen ya algunas de sus ideas, como la contradicción de un sistema con una alta capacidad de producción y bajos standards de consumo. Comienza la crítica a la actitud propia del empresario smithiano: la frugalidad y la vocación por el ahorro.

En su Tract on Monetary Reform de 1923 recomienda reemplazar el patrón oro, vinculado a la inestabilidad monetaria que causaba desequilibrios económicos, por un dinero más controlado por el Gobierno.

Entre la inflación moderada o la desocupación, opta por la primera.

Luego de la crisis del '29, se intentaba explicar el paro. Para los neoclásicos, representados entonces, entre otros por Pigou, la causa eran los altos salarios y atacaba a los sindicatos. Keynes explica la depresión por la escasez de la demanda global. Recomienda una elevación de los salarios pero no de tipo nominal sino a través del desarrollo del sistema de la seguridad social y una reducción de los impuestos, con el fin de estimular el consumo. Cuando la tensión entre el ritmo de crecimiento de la producción vinculado a la acumulación y al incremento en la productividad del trabajo causada por el progreso técnico y el ritmo en que se desarrolla la demanda efectiva se agudiza a favor de la primera surge la crisis con sus graves consecuencias.

El déficit fiscal aparece como una necesidad pues había que poner el énfasis en la inversión pública. La tasa de interés está determinada por la cantidad de dinero y por la preferencia por la liquidez. De modo que un aumento en la oferta monetaria haría bajar la tasa de interés, pero esto no ocurriría cuando nos hallamos en la trampa de la liquidez, que consiste en una tasa de interés suficientemente baja (alrededor de un $2 \%$ ) pues se

\footnotetext{
${ }^{1}$ Vazquez Presedo, V., Crisis y retraso, Buenos aires, Eudeba, 1978, p. 113.
} 
incrementaria la preferencia por la liquidez y asi todo aumento en la cantidad de dinero no tendría ninguna acción de estímulo en la inversión privada, cosa que según Keynes ocurría en los años '30. Razón por la cual recomendaba preferentemente la acción directa de las obras públicas para estimular la demanda efectiva.

\section{el Interés y el Dinero.}

Sus ideas se completan en su Teoria General de la Ocupación,

La consecuencia institucional más importante que surge del análisis de Keynes, es no sólo la recomendación sino la necesidad de una importante intervención del Estado en la vida económica. ¿Por qué?. Porque a diferencia de los economistas ortodoxos que consideraban que, dejado a su libre juego, las fuerzas del mercado conducirian al pleno empleo de los recursos productivos, a menos que existieran interferencias al mecanismo de la competencia, para Keynes no ocurre asi: la tendencia del sistema, en particular de la economia de su época es, permanecer en una situación de equilibrio estable con desocupación. ¿Y a qué se debe esto?. A la insuficiencia de la demanda efectiva. De modo que la acción estatal debe tender al incremento de la misma. Como ser el impuesto progresivo para elevar la propensión media al consumo de la comunidad; las obras públicas -inversión pública-; estímulo a la inversión privada, una política monetaria más concentrada y activa y mucho más flexible tendiente a incentivar la inversión, manteniendo lo más bajas posible las tasas de interés; apoyo a las políticas de incremento a los componentes sociales de los salarios, apoyo al sindicalismo.

¿Cuál es el sentido del keynesianismo?. A mi modo de ver tiende a salvar el sistema de vida occidental apoyado sobre la libre empresa, frente a las falencias del mercado para salir por si solo de los dramas de la época: recesión, desocupación. Por tanto cualquier comparación con el enfoque marxista es erróneo porque justamente representa un planteo opuesto, en cuanto a los intereses que defiende. Keynes se expresa despectivamente de Marx y su obra. Tampoco comparte el colectivismo soviético. Marx en el Tomo III de $E l$ Capital afirma que si bien el capitalismo en su marcha había superado las crisis ciclicas sucesivas que rigen su vida, llegaria la crisis final que colapsaria definitivamente el sistema. Cuando llegó el año 1929, muchos pensaron "Es la crisis que profetizó Marx". Los planes quinquenales soviéticos eran exitosos, el mercado fracasaba como mecanismo que permitiese el desarrollo creciente del sistema con plena ocupación.

Parecía no haber salida dentro del sistema mismo. Pero sí la hubo: en el plano de la realidad económica la experiencia del New Deal y otras como la alemana, y en el plano teórico la revolución keynesiana.

Comparto la idea del Dr. Vázquez Presedo: "Si la Teoria General representó una Revolución, ésta fue una revolución científica, 
revolución óptica, que ayudó a comprender mejor el mundo de las formas económicas. "revolucionario".

Sólo en este sentido puede ser Keynes considerado un

Las politicas que se derivaron de su pensamiento servirian para preservar las formas económicas más afines con la libertad individual y no para suprimirlas". 2

El New Deal - desde el ámbito de la experiencia - y el pensamiento keynesiano -desde la teoría- tendrán decisiva influencia en la historia y la política económica argentina a partir de la década del ' 30 .

Breve historia cum Politica económica peronista (1946-1953)

Antecedentes

La crisis del '29 interrumpió un proceso de crecimiento sostenido en la Argentina desde el último cuarto de siglo pasado. La Gran Depresión tuvo un impacto negativo en la economia argentina, debido a la fuerte vinculación externa de la misma. También en la Argentina como en el mundo comienza una era de creciente intervención del Estado en la economía.

En 1935 se crea el Banco Central de la República Argentina, al que son transferidas las funciones de redescuento y el control de cambios, que hasta ese momento cumplia el Banco Nación.

Se crean toda una serie de Juntas y Comisiones Reguladoras con el fin de ejercer control y asesoramiento a las empresas y de protección de precios. Así van apareciendo a lo largo de la década la Junta Nacional de Granos y otras en relación con diversos productos: carnes, yerba mate, azúcar, petróleo, algodón, etc.

Desde el gobierno se respaldan los diversos sectores de la economia; como el agropecuario a través de subsidios, establecimiento de precios mínimos, etc., y con el Tratado Roca-Runciman que se firma el 1 de Mayo de 1933, (con el objeto de asegurar el mercado de carne enfriada -chilled beef- británico).

${ }^{2}$ Vázquez Presedo, V., op. cit. , p. 124. 
Se realizan importantes inversiones públicas en infraestructura, se apoya al sector industrial a través de tarifas protectoras y el control de cambios.

Desde 1933, siendo Ministro de Hacienda el Dr. Federico Pinedo, se centralizan en un plan una serie de medidas para atacar el paro mediante la ejecución de obras públicas y el apoyo a la industria substitutiva de importaciones.

Los años más dificiles son los inmediatamente posteriores a la crisis.

A partir de 1933 se observa una recuperación, particularmente en los sectores de la construcción y la industria manufacturera.

Hacia 1940 comienzan a sentirse los graves problemas consecuencia de la guerra. Argentina pierde los mercados europeos, los precios caen, se deterioran los términos del intercambio, se acumulan stocks. El Plan Pinedo de 1940, elevado por el Poder Ejecutivo al Congreso, y que finalmente no se aprueba, es un ejemplo del cambio de actitud de la clase dirigente más lúcida. Proponía entre otras medidas: estímulo al crédito industrial y en particular a la construcción de viviendas económicas, compras de las cosechas por parte del Estado. Este programa debía ser financiado por el Banco Central con recursos de los bancos.

\section{Período 1943-1955}

En los años de guerra caen notablemente las importaciones, crece el superávit en el comercio exterior y por tanto, las reservas de oro, se desarrolla en general toda la economía y en particular el sector de la industria por sustitución de importaciones.

Con el fin de la guerra hay un notable incremento del comercio exterior, especialmente las importaciones que llegan en 1947 y 1948 a casi seis veces el promedio de los años de guerra. El comercio externo, en términos absolutos, más que se duplica a lo largo del periodo; además hay una diversificación por países, en desmedro de la participación relativa de Inglaterra y Estados Unidos en nuestras exportaciones. El sector agrícolaganadero constituye la mayor parte de nuestras exportaciones.

Las reservas internacionales crecen notablemente hasta el año 1946 y luego descienden, en particular durante el periodo 1946-1948.

A partir de 1944, se nota un incremento en los precios internos en relación a la década anterior- que se mantendrá a lo largo del periodo, con 
cifras topes en los años $1951(48,6 \%)$ y $1952(30,9 \%)$. A partir de 1953 se observa un ritmo de incremento decreciente.

En 1941 se crea la Corporación para la Promoción del Intercambio, bajo la supervisión del Banco Central, con el fin de estimular la exportación de productos no tradicionales, en particular en el Continente Americano.

A partir de 1943 -año de la revolución- hay un crecimiento de la economía, pero ya hacia fines de la década se observan serios problemas (como veremos más adelante), el incremento del gasto público y el déficit de los ferrocarriles y el I.A.P.I. generan un déficit fiscal.

En 1944 se crea el Consejo Nacional de Postguerra y se le confia al Vicepresidente de la Nación (Perón) la dirección de los estudios sobre el ordenamiento social y económico con el objeto de controlar la economía frente a las eventuales repercusiones del fin de la guerra.

El objetivo era estimular la producción "utilizando toda la mano de obra disponible" (véase ya la influencia keynesiana), estimular el progreso técnico, etc.

Perón dice "Aunque respetada la libertad económica, quedará sujeta a la inalienable función del Estado encauzar y ordenar la actividad a ella vinculada a fin de lograr el máximo bienestar general y el más alto nivel de empleo". (Nuevamente el influjo de Keynes).

El intervencionismo del Estado era cosa generalmente aceptada en esa época.

En 1946 se nacionaliza el Banco Central, y se aprueba la Ley sobre Régimen de garantía de los Depósitos Bancarios.

En octubre del '46 se presenta al Congreso el Primer Plan Quinquenal (1947-1951), donde se manifiesta -entre otras medidas en relación con todas las áreas de gobierno- el objetivo de la industrialización acelerada, mediante protección, subsidios, desgravaciones impositivas, tipos de cambio diferenciales y el apoyo del Banco de Crédito Industrial Argentino (dependiente del sistema del Banco Central).

Se propone un vasto programa de obras públicas. Se establecen censos a través del Departamento Nacional de Estadísticas y Censos, se promueve el crecimiento demográfico, la inmigración y la colonización, amplia acción social, acceso a la vivienda económica, promoción de la construcción, energía, transporte. Se tiende a la promoción del pleno empleo de los recursos.

Se procede a una industrialización a ultranza, creciente intervención del Estado, se unifica la política económica, primero a través de la Comisión Nacional de Postguerra y luego del Banco Central nacionalizado (1946). 
Se tiende a la creación de un mercado interno ampliado para lograr una mayor independencia de los mercado externos para nuestra producción. Para ello se promueve una redistribución del ingreso: reformas sociales, obras sociales, desarrollo del sindicalismo.

Esto tiende a hacer crecer la demanda efectiva -objetivo de tipo keynesiano-. Politica de nacionalizaciones de los servicios públicos (ferrocarriles, teléfonos, energía, etc.), propiedad de capitales extranjeros.

El sector agrario ve disminuir su participación relativa. A través del I.A.P.I. (Instituto Argentino de Promoción del Intercambio) se nacionalizó el comercio exterior.

Como consecuencia de este acelerado proceso de transformación profunda y unido a factores externos, se comienzan a producir dificultades: caen drásticamente las reservas, crece el déficit fiscal, suben los precios.

E1 Plan Marshall (1948) discrimina a la Argentina en cuanto a la posibilidad de colocar nuestros productos exportables. Esta situación se agrava a principios de la década del ' 50 con la Guerra de Corea, que genera graves dificultades para obtener los materiales críticos, combustibles, etc., necesarios para la industria, y esto agudiza el drenaje de divisas; las sequias de 1951 y 1952 que hacen caer fuertemente la producción agraria y por lo tanto las exportaciones. En 1949, como consecuencia de estas contrariedades cae Miguel Miranda, hasta ese momento el "Zar de la Economia" y es reemplazado por el Dr. Alfredo Gómez Morales, como Presidente del Banco Central y Ministro de Finanzas, luego de la reestructuración ministerial producida en la Reforma Constitucional de 1949.

En ese año -como veremos después- hay una reforma del Banco Central y del sistema monetario y bancario.

Para afrontar las mencionadas dificultades en 1952 se formula un plan cuyos objetivos centrales serán aumentar la producción y la productividad, especialmente agraria, disminuir el consumo (austeridad) y fomentar el ahorro.

Desde 1947 el Consejo Económico Nacional controlaba y coordinaba las normas en relación con la actividad económica.

El Segundo Plan Quinquenal (1953-1957), frente a las dificultades de crecimiento que presentaba la economia, apoya de una manera más armónica todos los sectores de la misma.

El pensamiento keynesiano y la política económica del peronismo 
Trataremos de ver: a) En qué años del período en estudio hubo influencia keynesiana en forma más evidente. b) En qué sentido se manifiesta el keynesianismo en el marco de la política económica de la época.

Creo que, efectivamente, hubo influencia keynesiana, en particular en el subperíodo 1946-1949; en el cual tuvo central participación en la conducción Miguel Miranda, que venía trabajando en el equipo económico de la Revolución desde el Consejo Nacional de Post Guerra.

En cuanto al segundo aspecto, considero que el keynesianismo constituía un medio y no un fin de la política económica. Los fundamentos o fines de lo que se hacía y pretendía hacer en el país responde a fuentes muy distintas.

E1 sentido del keynesianismo en los paises centrales del capitalismo es una acción coyuntural, de corto plazo para salvar el sistema (al menos en su versión originaria); mientras que en Argentina se intenta un profundo cambio estructural en lo económico y social que afecta todos los estratos de la vida económico-social y que se piensa como un gran programa de desarrollo económico de aliento histórico, por los plazos.

Perón en 1953, en un discurso dirigido a los industriales habla del desarrollo necesario de la industria pesada y piensa ya en un tercer Plan Quinquenal. Dice: "Queremos que el Segundo Plan Quinquenal al terminar nos encuentre con una pequeña industria pesada. Después vendrá un Tercer Plan Quinquenal, que será el de la expansión total de la industria, pensando en que la industria de todo orden vive siempre, un poquito, de la industria pesada". ${ }^{3}$ Este ambicioso programa de desarrollo y transformación histórica, que incluía entre otros aspectos: una fuerte intervención del Estado, un desarrollo industrial acelerado, las nacionalizaciones de los servicios públicos, la repatriación de la deuda pública, el intenso plan de inversión pública, la profunda revolución social y los procesos demográficos, migratorios, la creación de un amplio mercado interno, la diversificación del comercio externo, la importante transformación monetaria, bancaria y crediticia, el control del comercio exterior, etc.; todo ello excedía en mucho el sentido originario de las ideas keynesianas. Detrás de todo este programa de acción hay un fuerte nacionalismo.

${ }^{3}$ Perón habla a los industriales, Discurso pronunciado por el Presidente de la Nación al inaugurarse el Congreso General de la Industria, Ed. Banco Mundial, 18 de mayo de 1953. 
"Se vive un momento de economías nacionales dirigidas con propósitos nacionales". ${ }^{4}$

Es el intento de pasar de un estadio de país agrario semicolonial a un pais industrializado independiente; tal como explicitamente es proclamado.

En cuanto a la planificación dice Gómez Morales: "Primero planificaron los particulares, después las empresas y luego los monopolios, los trust y los cartels; y ahora planifica el Estado". 5

"Antes no se trataba de hacer frente a una coyuntura económica: se percibe una verdadera remodelación de la economia". 6

¿Cuál es el fin de la Revolución?. Garantizar la justicia social, nos dice Gómez Morales.

Entonces la planificación de la economia es un medio. "El gobierno de la revolución recurrió a la planificación de la economía como medio para dar concreción definitiva a sus postulados fundamentales"?

Veamos ahora algunos de los rasgos keynesianos -en el sentido que venimos señalando- en el periodo $1946-49$, si bien ya se manifiestan a partir de la revolución:

a) Intervención estatal creciente.

b) Redistribución del ingreso, incrementando la propensión media a consumir de la comunidad a través del incremento en los componentes sociales del salario, incremento del salario real, aumento de la demanda efectiva.

c) Una política monetaria bancaria y crediticia mucho más flexible, tendiente a la caida en la tasa de interés para promover la inversión.

d) Intensos programas de inversión pública.

e) Énfasis puesto en el objetivo prioritario del pleno empleo de los recursos.

Trataremos de ver con más detenimiento, ahora, cómo se manifiestan estos rasgos.

Comparemos la reforma bancaria de 1946 con la de 1935 . La creación del Banco Central.

Dice el mensaje del Ministro de Hacienda al Senado. "Todo plan de reorganización de nuestro sistema monetario y bancario debe tener en cuenta las caracteristicas fundamentales de la economía Argentina,

\footnotetext{
${ }^{4}$ Memorias del Banco Central de La República Argentina, 1946, p. 6.

${ }^{3}$ Gómez Morales, A., Discursos, Ministerio de Finanzas, p. 8, s/f.

${ }^{6}$ Gómez Morales, A., op. cit. , p. 11 y 12.

${ }^{7}$ Ibidem, p. 27.
} 
determinadas por nuestra condicion de pais eminentemente agrario... que ha absorbido y seguirá absorbiendo posiblemente capitales extranjeros".

El Artículo $3^{\circ}$ de la Carta Orgánica del B.C.R.A. dice en los parágrafos a y b: "El banco tendrá por objeto:

a) Concentrar reservas suficientes para moderar las consecuencias de la fluctuación en las exportaciones y las inversiones de capitales extranjeros sobre la moneda, el crédito y las actividades comerciales al fin de mantener el valor de la moneda.

b) Regular la cantidad de crédito y los medios de pagos adaptándolos al volumen real de los negocios".

Entonces el objetivo fundamental es mantener el valor de la moneda.

Sigue diciendo el mensaje del Ministro de Hacienda: "Las operaciones de inversión....sólo deben ser financiadas con el ahorro de la población, que asi se convierte en capital. El ahorro no se suple con crédito...".?

Veamos la diferencia con la reforma bancaria de 1946. Por el decreto 8503 del 25 de marzo de 1946, que pasa a ser la Ley 12.962, de Nacionalización del Banco Central, quedan sometidos a la superintendencia del B.C.R.A., el Banco Nación, el Banco de Crédito Industrial Argentino, el Banco Hipotecario Nacional, la Caja Nacional de Ahorro Postal, la Comisión Nacional de la Vivienda, el Consejo Agrario Nacional, la Corporación Nacional del Intercambio -antecedente del Instituto Argentino de Promoción del Intercambio- y el decreto 11.554 se refiere a la garantía de los depósitos bancarios.

El Artículo 3 dice (en el punto a): "El Banco tendrá por objeto:

a) Promover, orientar y realizar, en la medida de sus facultades legales la política económica adecuada para mantener un alto grado de actividades que procuren el máximo empleo de los recursos humanos y materiales disponibles y la expansión ordenada de la economía con vistas a que el crecimiento de la riqueza nacional permita elevar el nivel de vida de los habitantes de la Nación.

Vemos en este punto todo un programa de acción. El keynesianismo de estas ideas es evidente: búsqueda del pleno empleo, crecimiento del ingreso. El Banco Central nacionalizado pasa a ser el órgano principal de conducción de la política económica nacional (conducida por Miguel Miranda).

${ }^{8}$ Congreso Nacional, Cámara de Senadores, Mensaje del Ministro de Hacienda, 29 de enero de 1935, p. 602.

${ }^{9}$ Cámara de Senadores, 29 de enero de 1935, p. 606. 
Veamos ahora la reforma monetaria de 1949.

Se modifica, entre otros, el artículo primero. El Banco Central de la República Argentina pasa a depender del Ministerio de Finanzas, así como el resto de las entidades previamente dependientes de él.

Articulo $3^{\circ}$, en su punto a). Objeto:

a) Concentrar y movilizar reservas y ejercer el control de los cambios, para moderar los efectos que sobre el valor de la moneda y la actividad económica puedan tener las fluctuaciones del comercio exterior y los movimientos internacionales de capitales y su inversión.

El punto b) se refiere a la regulación del crédito y de los medios de pago... "para mantener un alto grado de ocupación y el poder adquisitivo de la moneda".

Es interesante esta especie de síntesis dialéctica entre el Banco de 1935 y el de 1946 (sólo en el sentido en que aqui nos referimos).

O sea se conserva el objetivo de un alto grado de ocupación a condición de que se mantenga el valor de la moneda.

Como hemos visto, la situación interna e internacional ya había cambiado hacia esta época. El keynesianismo se ve cada vez más atenuado. Ya la situación no era keynesiana y cada vez lo sería menos.

En el discurso del Ministro de finanzas, Dr. Alfredo Gómez Morales en la Cámara de Diputados de la Nación (Septiembre de 1949) hay algunas reflexiones remarcables. Dice, refiriéndose al Banco Central de 1935: "éramos y debíamos ser sólo un país productor agropecuario, nuestra industria en tales condiciones hubiera necesitado, en el mejor de los casos, medio siglo para tener algún significado. El gobierno de la Revolución no podía esperar, necesitaba cumplir su programa y hallar medios que le permitieran llevarlo a cabo, barriendo drásticamente con las opiniones interesadas en mantener al país en estado de dependencia colonial". ${ }^{10}$

Vemos que el intervencionismo estatal y las otras formas de keynesianismo son un instrumento para cumplir el programa de fondo: la independencia económica nacional.

Frente a la situación de 1946: las reservas de oro habían pasado de 1.400 millones de pesos (Setiembre de 1939) a 6.000 millones de pesos (Setiembre de 1946), se había desarrollado la industria nacional sustitutiva de importaciones, pero el equipo exigía renovación, había una gran demanda acumulada de bienes de consumo durables, stock de granos adquiridos por el

${ }^{10}$ Cámara de Diputados, Discurso del Ministro de Finanzas Dr. Gómez Morales, 16 de septiembre de 1949, p. 25. 
gobierno, situación de pleno empleo. En este marco el Poder Ejecutivo fijó los siguientes objetivos:

1) Cancelar la deuda pública externa.

2) Nacionalizar los servicios públicos de propiedad extranjera.

3) Crear una flota mercante.

4) Acelerar la industrialización del país.

5) Elevar el nivel de vida de los trabajadores. (Hasta aquí seguimos el discurso de Gómez Morales).

Como se ve hay en estos objetivos la intención de superar el anterior estadio de país agrario dependiente, para convertirlo en un país industrializado con el manejo nacional de las decisiones, con su propia flota para independizarse crecientemente de los mercados tradicionales (Inglaterra, Estados Unidos) y creando su propio mercado interno.

Nuevamente el keynesianismo fue necesario, pero en función instrumental.

Dice en el mismo discurso: "....debe reconocerse esta conclusión: que nuestra economía fue reactivada y que la redistribución de la renta fue facilitada" (p. 29).

A partir de alli (1949) cambian las condiciones, debido a las nuevas circunstancias: descenso en la producción agropecuaria por falta de mano de obra en ese sector, la fuerte caída de las reservas, el déficit fiscal y la suba de precios: "en consecuencia la política que adopte el Poder Ejecutivo habría de tener como punto de mira fundamental el mejoramiento y consolidación de nuestra producción agropecuaria" (p. 38).

El cambio de tónica (a partir de 1949) es visible respecto al período anterior. En las páginas 47 y 48 de dicho discurso el Dr. Gómez Morales dice referente a las ideas de Keynes: "el pensamiento de Keynes evoluciona paralelamente a la transformación mundial después de la guerra del 14 al 18 (...) luego (...) se convierte en ardiente defensor del sistema dirigido de papel moneda nacional, cuyos objetivos apuntaban hacia la estabilidad del nivel de precios interno". Más tarde "en Estados Unidos las ideas keynesianas fueron utilizadas por el New Deal de Roosvelt" (p. 47).

Como vemos, aparecen entremezclados elementos de la experiencia del New Deal y las políticas keynesianas.

Veamos otro pasaje del mismo discurso en que surge claramente el keynesianismo de las medidas, utilizadas como medio para lograr fines que, provienen de otras fuentes, que me parecen vinculadas a la Doctrina Social de la Iglesia (tema de la justicia social) y con el nacionalismo que venía de diversas fuentes como el G.O.U. (Grupo Obra de Unificación) y F.O.R.J.A. (Fuerza para la Organización Radical de la Joven Argentina), que inspiraron la doctrina peronista. 
Dice “.... se sentaba como una necesidad imperiosa alcanzar un nivel de máxima utilización de los recursos naturales y del trabajo nacional.

Por este medio se lograría el aumento de la renta nacional, to que permitiría aumentar el nivel de vida de la población del país, poniendo en práctica una adecuada política de redistribución de los ingresos, en forma tal que consultase los auténticos principios de justicia social por largo tiempo olvidados.

Simultáneamente con el logro de estos objetivos y como una condición indispensable para alcanzarlos, se hacía necesario conquistar la independencia económica del país, cuyos resortes fundamentales en el manejo de la riqueza continuaban todavía, en gran medida, bajo el control de intereses foráneos" (p. 59).

La reforma del ' 46 , argumenta, permite, por primera vez, una auténtica política económica de tipo nacional al arrancarle el manejo de dinero "a los intereses particulares de los grandes consorcios financieros" (Loc. cit.).

Y a continuación Gómez Morales cita a Pio XI en la Encíclica "Quadragésimo Anno": .... estos potentados son extraordinariamente poderosos cuando, dueños absolutos del dinero, gobiernan el crédito y los distribuyen a su gusto; diríase que administran la sangre de la cual vive toda la economía y que, de tal modo, tienen en su mana, por así decirlo, el alma de la vida económica, que nadie podría respirar contra su voluntad" (Loc. cit.).

Frente al tremendo poder del capital financiero concentrado, sólo el poder del Estado podía intentar enfrentarlo. De allí la intervención estatal. A partir de 1949 los nuevos objetivos de política económica son: aumentar la producción, en particular la agropecuaria, aumentar la productividad en la industria, desalentar la producción y consumo de bienes superfluos, planes de mecanización agraria, créditos a ese sector, presupuesto equilibrado, supresión de subsidios, reducción de la inversión pública, aumento de las tasas de redescuento y reducción de su volumen, reducción de créditos hipotecarios.

Como se ve claramente, nos alejamos de Keynes.

Como consecuencias de estas medidas, en los años 1950 y 1951, hay una ampliación del área sembrada, aumenta la producción agropecuaria, crecen las exportaciones, crecen las divisas, cae la tasa de inflación y crece la productividad. Los aspectos negativos: se incrementan los costos de los productos importados, materiales y materias primas esenciales y la sequía de 1951 traen como consecuencia el plan de 1952. Según el Dr. Ramón Cereijo, Presidente del Consejo Económico Nacional, los objetivos fundamentales son: ".... Aumentar la productividad y la producción en todos los órdenes; aumentar el volumen de saldos exportables; reducir las importaciones; estabilizar los precios que afectan el nivel de vida de la población; aumentar el 
poder adquisitivo de los salarios mediante el perfeccionamiento de los métodos de producción; fomentar el ahorro; consolidar la capitalización del país". ${ }^{11}$

Ahora estamos definitivamente en las antípodas de una situación y de una política económica keynesianas.

Los temas son: producción, productividad, racionalización, austeridad, ahorro, combate a la especulación.

A continuación reproduciré una conversación mantenida con el Dr. Alfredo Gómez Morales en el mes de octubre de 1983 como elemento probatorio de algunas de mis conclusiones

Autor: ¿Cómo caracterizaría Dr. Gómez Morales, la figura de Don Miguel Miranda y su política económica?

Dr. Gómez Morales: Miranda fue un audaz; el zar de la Economía hasta 1949. Alli la tomé yo. Miranda tenía mentalidad de hombre de empresa.Buscaba hacer buenos negocios. En cambio a mí siempre me tocó bailar con la más fea, es decir cuando estaban mal los términos del intercambio. Los Estados Unidos crearon un monopolio de compra, con lo que nos mataban por las dos partes: no podíamos o era muy dificil colocar nuestras exportaciones y por otro lado, nos costaba conseguir las importaciones esenciales, especialmente el combustible, que era vital para nosotros. Es una lucha, ve Ud.

Autor: Mi trabajo consiste en tratar de ver las relaciones que hubo, si es que fue así, entre el pensamiento keynesiano y la política económica argentina de posguerra. ¿Cuál es su opinión al respecto?.

Dr. Gómez Morales: Evidentemente se puso el acento a partir de Keynes sobre la demanda. Estaba en boga en esa época. Por tanto, sí, en efecto, inspiraba la economía del peronismo, pero también la del radicalismo y otros partidos, excepto los liberales.

El keynesianismo daba el apoyo teórico-económico con su gran prestigio, para las realizaciones no sólo del peronismo; porque antes comienzan las Juntas de Granos, de carnes, etc. Es decir los controles, protecciones, en fin, el incremento en la intervención del Estado, que es propio del keynesianismo.

El prestigio generalizado de que gozaba el keynesianismo, en esa época avaló, de algún modo, nuestra política. Si diez años antes se hubiera propuesto esa política (se refiere a la política económica implementada por el peronismo) hubiera parecido una locura. Pero entonces contaba con el aval de un economista del prestigio de Keynes.

11 Cereijo, R., El plan económico de 1952 y la consolidación de la prosperidad nacional, Conferencia del Ministro de Hacienda y Presidente del C.E.N., en la Bolsa de Comercio, 24 de marzo de 1952, Ed. C.E.N., 1952, p. 21. 
Autor: ¿Qué opina Dr., de la exposición de esta teoría, que hace Raúl Prebisch en su Introducción a Keynes del año 1947 ?

Dr. Gómez Morales: Prebisch tiene una interpretación razonable de Keynes. Ahora bien yo me forme más con la anterior economía clásica.

Autor: Keynes dice que, luego de aplicada su receta y llegado al pleno empleo son válidos los supuestos y el razonamiento clásico (neoclásico).

Dr. Gómez Morales: Y es así. Nosotros en 1947 ya teníamos el pleno empleo. A partir de allí se siguió la política anterior, emisionista, de crédito abundante, etc., política de dinero bastante barato. Esa politica fue inflacionaria en ese momento, porque ya existía, el pleno empleo. Alli es donde yo intervine. Por ejemplo, en 1949, dando créditos, pero selectivos. No se puede dar lo mismo al especulador que al productor o al consumidor.

Además, apliqué lo que yo llamaba el "uno y uno": el que solicitaba crédito debía aportar él la mitad para comenzar la empresa, porque si no, era casi un regalo. Debía demostrar que participaba también, es decir, ver yo que tenia capacidad e intención de producir y hacer rentable la inversión.

No se podía seguir con el anterior keynesianismo. La política económica es un arte. No es cuestión de teoría, es una cuestión práctica.

Teníamos por el ' 52 alrededor de un $40 \%$ de inflación anual. Tuvimos que hacer una política anti-inflacionaria. Por tanto no keynesiana. Se comía pan negro, pero la gente lo aceptaba porque la ley era pareja para todos. Todos comían el mismo pan. Además hicimos una amplísima difusión del Plan de 1952.

Como consecuencia de la política europea que cortaba el triángulo tradicional: comprar a Estados Unidos para vender a Europa, teníamos que buscar, por tanto, otros compradores.

Así que el problema era: inflación, por la falta de producción para satisfacer la demanda (inflación de costos por altos precios de los insumos importados).

Además, Estados Unidos vendía sus productos agropecuarios, compitiendo con nosotros, y nosotros nos quedamos sin compradores, $\mathrm{o}$, en todo caso, nos compraban, pero más barato.

La Ley de Say dice que la oferta crea su propia demanda pero no es así.

Con relación a sus inquietudes fue muy importante la experiencia del New Deal, que está en la línea del keynesianismo. Roosevelt tuvo que actuar enfrentándose a la Suprema Corte de Justicia para imponer sus planes (de intervención del Estado en la economía). Quiere decir, que fue revolucionario. Cuando el mercado no es adecuado o suficiente para la buena marcha de la economía, el Estado debe intervenir. 
Entonces Keynes implicaba una revolución. El New Deal es de inspiración keynesiana. (Autor: Uno lo podria interpretar como un keynesianismo "avant la lettre").

Esa experiencia del New Deal, consecuencia de la crisis del '29 es la inspiración principal de nuestros proyectos y realizaciones económicas.

Autor: ¿Y la experiencia alemana?

Dr. Gómez Morales: No. No se relaciona para nada con la

nuestra.

\section{Autor: ¿Y la italiana?}

Dr. Gómez Morales: Perón estuvo en Italia. Lo que tomo Perón de ahí, es la idea de pasar de un complejo de inferioridad (país colonizado) a una idea de fuerza. De voluntad de crecer y ser fuertes y grandes. Cosa que logró Musolini. Ahora bien, cuando yo tomé los asuntos económicos, después de Miranda, ya se había logrado el pleno empleo.

Cuando en el nuevo gobierno (se refiere al año 1974) se había caído en una inflación latente, no se podía seguir avalando desde el Banco Central esa política emisionista. Por eso renuncié. Al mes y medio me llaman para elaborar un plan. Yo pedí el apoyo político: había que contener salarios, gasto público, para contener la inflación, pero necesitaba apoyo. No lo tuve. Sí, lo tuve en 1952, cuando Perón me dijo: "Ud. no solo tendrá mi apoyo, sino el de todos". Yo estaba a 20 metros de Perón.

Permanentemente me llamaba para consultarme sobre cualquier problema económico.

Perón era inteligente, fue la estructura más efectiva que se logró instrumentar; alli centralizaba todo. Como Secretario Económico del Poder Ejecutivo poseía un cargo más alto que ministro, era el asesor directo del Presidente.

Para comprender la diferencia entre la política seguida por Miranda y la mía hay que colocarse en ese momento histórico. Aldo Ferrer se equivoca cuando analiza la economía peronista del ' 50 , muestra una regresión o reacción frente a lo positivo del periodo anterior, (Miranda) en relación con nuestra política de apoyo al campo.

Luego de la Segunda Guerra el objetivo principal fue que no se destruyera la industria que había crecido bajo la protección de la guerra, por sustitución de importaciones.

Autor: ¿Por qué Perón no lo puso a Ud. en el Ministerio de Economía luego de su retorno al país?

Dr. Gómez Morales: El pensaba repetir la experiencia anterior. En primer lugar, un hombre audaz, de empresa, y luego, alguien para ordenar y estabilizar. Me dijo: "En poco tiempo, un año, lo pongo a Ud.". Pero ya no le daba la salud. Estaba enfermo.

Autor: Volviendo a la influencia ejercida por Keynes... 
Por ello, el I.A.P.I., las protecciones, el control de cambio, los fomentos, etc., todo lo cual implicaba fuerte intervención estatal. Miranda llevaba adelante esa politica, pero en forma indiscriminada. Yo estuve en la faz de la estabilización. Pero no significaba negar la política anterior, sino el ritmo. Con Miranda diferíamos en el ritmo.

Yo trataba de ir logrando las conquistas paulatinamente a medida que se iban dando las condiciones.

A mí me tocó actuar en los malos momentos; cuando los términos del intercambio nos desfavorecian. Primero, después del Plan Marshall y la Guerra de Corea. Y la preparación para la guerra que casi se produce en el '48, donde se arma un puente aéreo en Berlín.

Autor: ¿Por qué lo acusaron de reaccionario?

Dr. Gómez Morales: Porque apoyaba al agro. Porque tenía una política prudente en materia de moneda y crédito, menos pródigo en su concesión.

Luego de 1952 el problema era la caída de la producción y la inflación de costos, porque la producción era menor que la demanda. Entonces yo no abandoné mis estudios de economía anteriores a Keynes -que era la mayor parte-. No dije: "Tomo Keynes y dejo el resto". No. Por ello en cierto modo es verdad que una vez logrado el pleno empleo comienzan a valer los postulados clásicos. Por ello -pienso yo- volvia a aparecer un problema de oferta-producción. Debido a dos sequías -1951 y 1952- y a la guerra de Corea, con lo que nos veíamos en dificultades para conseguir insumos esenciales con el consiguiente perjuicio para la industria y la producción .Esta cae y los precios suben (inflación por costos). La demanda interna no disminuye en la misma medida. La oferta -producción- no puede responder a esa demanda y en consecuencia, hay inflación de costo con la de demanda.

Autor: Fue una época de cambios en el mundo, evidentemente muy grandes.

Dr. Gómez Morales: Claro. Lo que ocurre es el cambio en la situación internacional: La posguerra, el Plan Marshall, la recuperación europea, el F.M.I. (Fondo Monetario Internacional), el B.I.R.F., etc., toda esa economía internacional pensada para beneficio de los paises centrales y perjuicio del nuestro. Perón, en una época se apoyó en Gran Bretaña -que necesitaba nuestras carnes- frente a la acción deletérea de los Estados Unidos (monopolio de compra). Éstos colocaban su producción agropecuaria subvencionada en los países europeos y al mismo tiempo en juego de pinzas nos hacía retacear nuestros insumos esenciales que Estados Unidos necesitaba para el rearme. Entonces cuando yo tomé el manejo de la economía, en el '49, tuvimos que vender los productos agropecuarios acumulados, que se estaban pudriendo, en operaciones realizadas con mucho cuidado y paciencia. 
En el periodo 1946-1949 se dan los procesos de cambio - La Nueva Argentina- .

Pero a partir de alli -1949- comienzan a sentirse las consecuencias de esa revolución, debido a factores internos y externos que se agudizan en los años siguientes por los acontecimientos mencionados. En esa época hay un gran incremento de la población, migración del campo a la ciudad, inmigración, industrialización, nacionalización de servicios públicos, cambio social -obras sociales-, incremento del salario real, que hace crecer la demanda, fuerte mercado interno en el que se apoya la industria nacional.

Pero ésta necesita ser provista de combustible y ciertos insumos vitales del exterior. Para ello son necesarias las exportaciones agropecuarias, con las que pagar esas importaciones de insumos esenciales.

El abandono del patrón oro, que nos atenazaba en la contracción, y que posteriormente fue reemplazado por el F.M.I y el B.I.R.F., implicaba un cambio en la concepción de tenencias de oro y divisas.

¿Para qué sirven?. Es el ahorro de la comunidad y por lo tanto, son para gastarlos cuando se necesite. Pero no derrocharlos. Hay que ser muy cuidadosos en el otorgamiento del crédito.

\section{Conclusiones}

A modo de breve conclusión, queda suficientemente demostrado que:

A) Hubo keynesianismo en particular en el período 1946-1948.

B) Tuvo un sentido instrumental. Medio para cumplir objetivos que provenían de otras fuentes.

C) Esas otras fuentes, creo que exceden el ámbito estrictamente propio de la teoría económica, pero no por ello y debido a la efectividad de su acción ideológica, podemos dejar de mencionarlos. 
D) Son por un lado, las ideas nacionalistas, que tienden a la superación de una situación que se califica de colonial y por tanto, el logro de la independencia económica.

E) Estas ideas parecen provenir del G.O.U (Grupo Obra de Unificación) que gestó la revolución de 1943, de donde surge el movimiento peronista y de F.O.R.J.A. (Fuerza para la Organización Radical de la Joven Argentina), que influye fuertemente en las ideas del peronismo. $Y$, por otro lado, la Doctrina Social de la Iglesia, por ejemplo la Encíclica "Quadragésimo Anno" (Pio XI, 1931), en cuanto al ideario de la justicia social.

F) El auge y el prestigio de que gozaban las teorias de Keynes y las politicas económicas que de ellas surgian, permitió la realización del proyecto económico peronista, sin generar exageradas reacciones.

G) El keynesianismo se manifiesta -en el periodo estudiado- particularmente en la "era" Miranda.

H) El proyecto económico peronista excede el simple calificativo de "keynesiano", porque, es un intento de transformación estructural profunda de connotaciones históricas, pensado en plazos muy largos. En la cual la fase keynesiana es sólo una etapa.

I) Además de la teoría keynesiana influyó sobre la politica económica peronista la experiencia de New Deal y la propia experiencia argentina posterior a la crisis del 29.

Alberto J. Vercesi

Departamento de Economia

Universidad Nacional del Sur 


\section{BIBLIOGRAFIA}

Banco Central de la República Argentina, Memorias, 1940-1955.

Banco de la Nación Argentina, Memorias.

Cafiero, Antonio, Cinco años después, Buenos Aires, 1961.

Cámara de Senadores, Anales, 29 de enero de 1935, 21 de diciembre de 1946, Reformas Bancarias de 1935 y 1946 respectivamente.

Cereijo, Ramón A. , El plan económico de 1952 y la consolidación de la prosperidad nacional, Consejo Económico Nacional, Buenos Aires, s/f.

........, Sentido y alcance del plan ecomómico para 1952, Conferencia en Facultad de Ciencias Económicas, Buenos Aires, Abril 1952.

-....... - Discursos y declaraciones del Ministro de Hacienda y Presidente del Consejo Económico Nacional en EE.UU., 1950.

Díaz Alejandro, C.. Ensayos sobre la historia económica argentina, Buenos Aires, Ed. Amorrortu, 1983.

Di Tella , Guido y Zymmelman, Manuel, Las etapas del desarrollo económico argentino, Buenos Aires, Eudeba, 1967.

Escudé, Carlos, Gran Bretaña, EE. UU. Y la declinación argentina (1942 - 1949), Buenos Aires, Ed. de Belgrano, 1983.

_....... Las restricciones internacionales de la economia argentina (1945-1949), Desarrollo Económico, Vol 20, № 77, abril-junio 1980 , p. 3-40.

Gómez Morales, Alfredo, Discursos ante la Convención Nacional Constituyente, 27 de enero de 1949.

----, Politica económica peronista, Ministerio de Finanzas, Buenos Aires. 
-........ Mensaje al Congreso de la Nación en ocasión de la reforma bancaria y monetaria de 1949, Ministerio de Finanzas, septiembre de 1949.

-.-.--- Discurso del Ministro de Finanzas ante la Cámara de Senadores. 23 de septiembre de 1949.

-...n-.-, Plan económico de 1952. Conferencia pronunciada por el Ministro de Finanzas, 27 de mayo de 1949. Ministerio de Finanzas, 1952.

Lattuada, Mario, La politica agraria peronista,1943-1983, Buenos Aires, Centro de Desarrollo de América Latina, 1986.

Little,Walter, La organización obrera y el estado peronista (1943-1955),

Desarrollo Económico, Vol. 19, No 75, octubre - diciembre 1979, p. $330-370$.

Llach, Juan J., El plan Pinedo en 1940. Su significado histórico y los origenes de la economía politica del peronismo, Desarrollo Económico, Vol. 23 , $N^{\circ} 92$, enero - marzo 1984 , p. 515-558.

- Estructura ocupacional $y$ dinámica del empleo en la Argentina. Sus peculiaridades, 1947-1970, Desarrollo Económico, Vol. $17, \mathrm{~N}^{\circ} 68$, enero - marzo 1978 , p. $539-592$.

Ministerio de Finanzas de la Nación, El segundo plan quinquenal y el Mimisterio de Finanzas, Buenos Aires, 1953.

Montuschi, Luisa y Vázquez Presedo, Vicente, Plan y laissez faire en la economía contemporánea, Buenos Aires, Ed. Macchi, 1970.

Murnis, Miguel y Portantiero, Juan C. , Estudios sobre los origenes del peronismo, Buenos Aires, Ed. Siglo XXI, 1971.

Perón, Juan D., Discursos y Canferencias. Mensajes, Buenos Aires, Consejo Económico Nacional, 1952.

-...-..- Perón habla a los industriales. República Argentina, Ed. Banco Mundial, , 1953. Plan Quinquenal (1947-1951), Buenos Aires, Ed. Primicias. 
Rapoport, Mario, Economía e historia , Buenos Aires, Ed. Tesis, 1988.

-....... La política británica en la Argentina a comienzos de la década de 1940, Desarrollo Económico, Vol. 16, № 62, julio - septiembre 1976, p. 203-228.

Scenna, Miguel A., F.O.R.J.A., Una aventura argentina, Buenos Aires, Ed. La Bastilla, 1972.

Skupch, Pedro, Nacionalización, libras bloqueadas y sustitución de importaciones, Desarrollo Económico , Vol 12, № 47 , octubre diciembre 1972, p. 477-495.

Vázquez Presedo, Vicente, Crisis y retraso. Argentina y la economia internacional entre las dos guerras, Buenos Aires, Eudeba, 1978.

, Cambios en la distribución del poder económico internacional en la segunda postguerra, Buenos Aires, Academia Nacional de Ciencias Económicas, 1981.

-...-..... Sobre la concentración del poder monetario y la evolución reciente del sistema monetario internacional, Buenos Aires, Academia Nacional de Ciencias Económicas, 1982.

-.-...- Sobre la inesperada persistencia del término teórico - histórico imperialismo. Buenos Aires, Academia Nacional de Ciencias Económicas, 1983.

Villanueva, Javier, El origen de la inchustrialización angentina, Desarrollo Económico, Vol. 12, No 47, octubre - diciembre 1972, p. 451-477. 